\title{
Diagnostic tests in Raynaud's phenomena in workers exposed to vibration: a comparative study
}

\author{
N OLSEN
}

From the Departments of Clinical Physiology and Nuclear Medicine, Hvidovre Hospital and Rigshospitalet, University of Copenhagen, DK-2100, Copenhagen Ø, Denmark

ABSTRACT Four objective tests to evaluate Raynaud's phenomena (RP) in workers exposed to handarm vibrations were applied on 23 exposed men with RP (vibration induced white finger 18, primary Raynaud's phenomenon 5), 56 exposed men without RP, and 15 male controls. Finger systolic blood pressure was measured by a cuff and strain gauge technique after combined body cooling and finger cooling during five minute ischaemia to $30^{\circ}, 15^{\circ}$, and $6^{\circ} \mathrm{C}$. An attack of RP was detected as a zero pressure, FSP(0) test, whereas a pressure, reduced to a value below the normal $95 \%$ confidence limit at $6^{\circ} \mathrm{C}$, was regarded as an abnormal response, $\mathrm{FSP}(\mathrm{A})$ test. A hand cooling, preceded by 30 minute body precooling, was performed in water at $10^{\circ} \mathrm{C}$ during five minute ischaemia. The finger colours after hand cooling were evaluated by a directly visual inspection, FCV test, and by a blind assessment of slides of the photographed hand, FCS test. A medical interview was used as a method of reference. The sensitivity did not differ significantly between FSP(0) $(74 \%)$, FCS $(61 \%)$, and FCV $(57 \%)$ $(\mathrm{p}>0 \cdot 10)$. FSP(A) had a significantly higher sensitivity $(96 \%)$ and lower specificity $(64 \%)$ than those of FCV and FCS $(p<0.0005)$ and of FSP(0) $(\mathrm{p}<0.05)$. Six of the seven men with a false positive FSP(0) had a positive FCV or FCS, and the seventh had a history of previously active RP. The six false negative FSP(0) test results did not correspond significantly to milder cases of RP $(p>0 \cdot 20)$. The results indicate that a finger colour test may be as valuable as a $\operatorname{FSP}(0)$ test for diagnostic purposes. FSP(A) only indicates if a cold response is exaggerated and does not diagnose RP. The pressure measurements may further be of guidance in evaluating preventive measures and effects of treatments for RP.

A medical interview is generally accepted for diagnosing Raynaud's phenomena (RP) in workers exposed to hand-arm vibrations. From the clinical and medicolegal points of view, however, objective diagnostic tests are needed. The main problem in objective diagnosis of RP is related to the episodic nature of vascular spasms that must be provoked under test conditions. The nosographic sensitivity of the classic cooling test, in which the finger colours are evaluated by visual inspection after hand cooling, varies considerably in workers exposed to vibration.' Measurements of finger systolic blood pressure after finger cooling ${ }^{2}$ has been suggested ${ }^{34}$ to be superior to the hand cooling test but its value depends on which test criterion is used. The lower normal limit of the reduced pressure (FSP(A)) after finger cooling has been used as a criterion ${ }^{56}$ and has been compared with a hand cooling test in a single study. ${ }^{6}$ Nevertheless,

Accepted 22 June 1987 only a reduction in pressure to zero ( $\mathrm{FSP}(0)$ criterion) detects an attack of RP with complete arterial closure. ${ }^{27}$ The FSP $(0)$ test and the hand cooling testthat is, the finger colour test-have never been compared in the same population.

In the present study the following four objective tests were compared: $\operatorname{FSP}(0), \operatorname{FSP}(A)$, a direct evaluation of finger colours by visual inspection of the cooled hand (FCV), and a blind evaluation of finger colours as seen on slides of the photographed cooled hand (FCS). As the generally accepted criterion, a medical interview was regarded as the method of reference. All tests were applied on 23 men exposed to vibration with RP, 56 exposed men without subjective finger symptoms, and 15 male controls.

\section{Subjects and methods}

All participants were guaranteed personal anonymity concerning their diagnoses and gave informed consent 
to the study, which was approved by the local ethical committee. The vibration workers comprised 37 workers (21 chain sawyers, 16 ex-sawyers) from two forest districts in Jutland and $\mathbf{4 2}$ active road workers of the municipality of Copenhagen. The road workers carried out repairs and minor constructions on roads, wires, and pipes and mainly used pneumatic hammers, pneumatic chisels, and vibrating plates.

The 37 forestry workers were recruited from 39 lumberjacks investigated five years previously, ${ }^{8}$ excluding two subjects because of emigration and medical treatment for arterial hypertension. The 42 road workers were recruited from a total of 340 road workers by means of their answers to a questionnaire on the use of vibrating hand tools and finger symptoms. Those who reported finger symptoms and an age and exposure matched group without finger symptoms were invited for a medical interview. The cold provocation tests were performed on 47 otherwise healthy road workers. Results were not obtained for five of these men for technical reasons. The remaining 42 exposed road workers were included in the study. Thus the study comprised a total of 79 exposed men. Of these 23 had RP: 18 had vibration induced white finger (VWF) ${ }^{9}$ whereas the remaining five probably had primary Raynaud's phenomenon (PRP) ${ }^{10}$ as evaluated from the interview. No other types of RP were included. Fifteen controls were selected according to the following criteria: outdoor working man, only worked with vibrating tools for less than one hour at a time and with intervals of at least one month, no metabolic or vascular disorders, no medication, and no secondary causes of RP. Thus minor use of vibrating tools was accepted as only a few subjects had never been exposed to hand-arm vibrations. Table 1 gives the characteristics of the investigated groups.

The interview comprised "passive" or neutral ques-

Table 1 Characteristics of vibration exposed men and male controls. Stages 1, 2, 3 and 4 refer to the Taylor-Pelmear stage assessments of $R P, A S P, F S P_{30}$, and $A S P-F S P_{30}$ denotes arm systolic blood pressure, finger systolic blood pressure at $30^{\circ} \mathrm{C}$, and systolic pressure gradient from upper arm to finger at $30^{\circ} \mathrm{C}$, respectively. Values are given as numbers or as the median with range in parentheses.

\begin{tabular}{|c|c|c|c|}
\hline & \multicolumn{2}{|c|}{ Vibration exposed men } & \multirow{2}{*}{$\frac{\text { Male controls }}{\text { Without RP }}$} \\
\hline & With $R P$ & Without $R P$ & \\
\hline $\begin{array}{l}\text { No of men } \\
\text { Age (y) } \\
\text { Exposure period (y) } \\
\text { Men in stages } \\
\quad 1,2,3,4 \text { (No) }\end{array}$ & $\begin{array}{l}23 \\
55(26-72) \\
13(2-28)_{n=22} \\
1,10,12,0\end{array}$ & $\begin{array}{l}56 \\
43(23-70) \\
16(2-36)\end{array}$ & $\begin{array}{l}15 \\
40(23-62)\end{array}$ \\
\hline $\begin{array}{l}\text { ASP }(\mathrm{mm} \mathrm{Hg}) \\
\mathrm{FSP}_{30}\left(\mathrm{~mm} \mathrm{Hg}^{\mathrm{H}}\right) \\
\text { ASP-FSP }_{30} \\
(\mathrm{~mm} \mathrm{Hg})\end{array}$ & $\begin{array}{c}135(110-210) \\
120(80-160) \\
15(0-70)\end{array}$ & $\begin{array}{l}130(115-175) \\
118(90-165) \\
15(-10 \text { to } 45)\end{array}$ & $\begin{array}{l}130(120-175) \\
115(105-160) \\
15(0-30)\end{array}$ \\
\hline
\end{tabular}

No significant difference between groups $(p>0 \cdot 10)$. tions concerning possible finger symptoms according to the principle that the subjects should themselves describe their symptoms. From this description the physician assessed if the subjects had a convincing history of RP, defined as a history of cold provoked episodes of well demarcated blanching in one or more fingers. Diffuse pallor of the fingers and palms in cold weather and a white colour of the fingers immediately after the hand grip was relaxed from the tool was not considered as a RP. VWF was defined as RP with first appearance after professional use of vibrating hand tools and without other probable causes.9 PRP fulfilled the clinical criteria demanded by Allen and Brown. ${ }^{10}$ The severity of RP was graded according to the Taylor-Pelmear stage assessments. ${ }^{9}$ This grading scale goes from stage 0 to stage 4 with increasing severity of symptoms and with stage 0 as a stage without symptoms. ${ }^{9}$ The stage assessments for the subjects with RP are given in table 1 . RP had ceased if no episodes were noticed during the past two years. ${ }^{.1}$ The five years reproducibility of the diagnosis of RP in 1978 was estimated in 37 forestry workers by interviews performed in $1978^{8}$ and repeated in 1983 by the same physician. No subjects showed ischaemic or atrophic signs of the fingers at the interview.

The subjects were investigated in the supine position and dressed in indoor clothing after at least 10 minutes of rest with the fingers at heart level. Room temperature was, on average, $18^{\circ} \mathrm{C}$. Body cooling was performed from 10 minutes before the measurements by a cooling blanket perfused with water at $8-12^{\circ} \mathrm{C}$. In subjects with RP the finger most frequently displaying episodes of RP was studied. In the remaining subjects the same fingers (2-4 fingers) were used as in men with RP. Finger systolic blood pressure was measured by a cuff and strain gauge technique ${ }^{12}$ after cooling the midphalanx during five minutes ischaemia ${ }^{2}$ to $30^{\circ}, 15^{\circ}$, and $6^{\circ} \mathrm{C} .{ }^{13}$ The pressure at the lower two temperatures was expressed as a percentage of the pressure at $30^{\circ} \mathrm{C}$ (FSP\%), corrected for changes in arterial blood pressure during the investigation..$^{13}$ An attack of $\mathbf{R P}^{7}$ was defined as a zero pressure at one of the two lower temperatures ( $\mathrm{FSP}(0)){ }^{2}$ An abnormal vasoconstrictor response to cold, $\operatorname{FSP}(\mathrm{A})$, was defined as a FSP\% below 58 , which was the lower normal $95 \%$ confidence limit at $6^{\circ} \mathrm{C}$ in 20 controls never exposed to hand-arm vibrations. ${ }^{813}$ Arm systolic blood pressure was measured auscultatorily with a $12 \mathrm{~cm}$ broad cuff when the finger was thermostated at $30^{\circ} \mathrm{C}$. Table 1 gives pressures at $30^{\circ} \mathrm{C}$. The finger systolic blood pressure at $30^{\circ} \mathrm{C}$ did not differ significantly between the three groups ( $p>0.70$, table 1$)$ indicating that the differences in FSP\% are due to differences in vasoconstrictor responses to cold. The systolic pressure gradient from upper arm to finger at $30^{\circ} \mathrm{C}$ (table 1) was increased in one subject with VWF and two exposed 
men without $\mathrm{RP}$ when compared with the upper range $(40 \mathrm{~mm} \mathrm{Hg})$ of 20 non-exposed controls. ${ }^{8}$ This indicates that most of the subjects investigated were without a significant obstructive element in the supplying arteries. ${ }^{14}$

A hand cooling test was performed 15 minutes after measurements of FSP and at least after 30 minutes body cooling. The same hand was studied as in the pressure test. The examiner compressed the brachial artery for one minute while the subject clenched his fist repeatedly to empty the vessels of blood. With this procedure the fingers usually turned pale. A cuff placed around the wrist was suddenly inflated to a suprasystolic arm blood pressure. The hand was submerged up to the middle of the palm in well stirred water at $10^{\circ} \mathrm{C}$. After five minutes cooling during ischaemia the hand was dried lightly with towels. The cuff was released and the hand was placed with its back on a black cloth equipped with a colour plate (Kodak color control patches, Eastman Kodak Company, 1977). The hand and the colour plate were photographed (Kodak Ectachrome 200 DIN professional film EPD 135-36) one minute after the cuff was released. By visual inspection the finger colours were compared with the colours of the plate from 45 seconds after the release of the cuff. A well demarcated acral pallor or a pale violet colour of one or more fingers was defined as an episode of RP(FCV). ${ }^{710}$ The duration of an episode and the fingers affected were recorded. The finger colours on the slides were evaluated blindly (FCS). All slides were assessed twice in different and random order with an interval of three weeks at least six months after hand cooling was performed.

The sensitivity of a test expressed the incidence of true positive results obtained in subjects with RP. The specificity of a test expressed the incidence of true negative results obtained in subjects without RP. The predictive value of a positive test result was defined as the percentage of true positive results in all the exposed men.

Statistical evaluation was performed by nonparametric statistics with a significance limit of 0.05 (two tailed unless otherwise stated). The difference in nominal values between more than two related samples was tested with the Cochran Q test followed by the McNemar test corrected for continuity, or by the Sign test if the expected frequencies were less than five. The difference in nominal values between two independent samples was tested with the chi squared test with Yates's correction, or with the Fisher exact probability test if numbers were 60 or less. The difference in numerical values (ordinal or interval) between more than two related samples was tested with Friedman two way analysis of variance followed by the Wilcoxon matched pairs signed rank test. The difference in numerical values between more than two independent samples was tested with the Kruskall-Wallis one way analysis of variance followed by the Mann-Whitney rank sum test. The reproducibility of a test result was expressed by the estimated kappa coefficient $(k) .{ }^{15}$ The $95 \%$ confidence limits of a given sensitivity, specificity, or predictive value of a positive test result was estimated from the binomial distribution. Values are given as numbers or median (range).

\section{Results}

The diagnosis of RP was disagreed with in one of 37 forestry workers at interviews repeated with a five years interval $(k=0.94)$. This subject was classified as having VWF at the interview in $1978^{8}$ but denied any actual or previous history of RP at the interview in 1983. The diagnosis was disagreed with in two of 94 subjects at repeated FCS evaluations $(\mathrm{k}=0.93)$.

Table 2 gives the sensitivity and specificity of the four objective tests. These values did not differ significantly between FSP( 0$), F C S$, and FCV $(p>0 \cdot 10)$. FSP(A) had a higher sensitivity and lower specificity than FCV and FCS $(p<0.0005)$ and FSP(0) $(\mathrm{p}<0.05$, one tailed) in exposed workers. The predictive values of a positive test result were in 79 exposed men (prevalence of RP $=0.29$ ): FCV 76\% (50-93), FCS $74 \%$ (49-91), FSP(0) $71 \%$ (49-87), FSP(A) $52 \%$ (36-68). FSP(0) and the finger colour tests were disagreed with in five men with RP and one exposed subject without RP. FCV and FCS were disagreed with in one man with RP and three men without RP. Six of the seven men with a false positive FSP $(0)$ had a positive FCV or FCS, and the seventh had a history of

Table 2 Comparison of tests to diagnose Raynaud's phenomena $(R P)$ in vibration exposed workers. The test criteria were as follows: finger colours of RP after hand cooling as evaluated by visual inspection (FCV) or by a blind assessment of slides of the photographed, cooled hand (FCS); a zero systolic blood pressure in the cooled finger (FSP (0)); and a reduction in FSP of the cooled finger to a value below $58 \%$ of the pressure at $30^{\circ} \mathrm{C}(\operatorname{FSP}(A))$. $F S P(A)$ is not regarded as measuring an attack of $R P$. Values are given as percentage (\%) with $95 \%$ confidence limits of the binomial distribution in parentheses

\begin{tabular}{|c|c|c|c|}
\hline \multirow[b]{2}{*}{ Test } & \multicolumn{2}{|c|}{ Vibration exposed men } & \multirow{2}{*}{$\begin{array}{l}\text { Male controls } \\
\text { Without RP } \\
\text { (n=15) } \\
\text { Specificity }(\%)\end{array}$} \\
\hline & $\begin{array}{l}\text { With RP } \\
(n=23) \\
\text { Sensitivity (\%) }\end{array}$ & $\begin{array}{l}\text { Without RP } \\
(n=56) \\
\text { Specificity (\%) }\end{array}$ & \\
\hline $\begin{array}{l}\text { FCV } \\
\text { FCS } \\
\text { FSP(0) } \\
\text { FSP(A) }\end{array}$ & $\begin{array}{l}57(35-77)^{*} \\
61(39-80)^{*} \\
74(52-90)^{* *} \\
96(78-100)\end{array}$ & $\begin{array}{l}93(83-98)^{*} \\
91(80-97)^{*} \\
88(76-95)^{* *} \\
64(50-77)\end{array}$ & $\begin{array}{c}100(78-100) \\
100(78-100) \\
100(78-100) \\
87(60-98)\end{array}$ \\
\hline
\end{tabular}

Significantly different from FSP(A) in same group $\left({ }^{*} p<0.0005\right.$; ${ }^{* *} p<0.05$ one-tailed). No significant difference between FCV, FCS, and $\operatorname{FSP}(0)$ in same group $(p>0 \cdot 10)$. No significant difference in same test between groups without RP $(p>0 \cdot 10)$. 
previously active VWF. The subjects with a false negative $\mathrm{FSP}(0)$ comprised five men in stage 2 and one in stage $3(p>0 \cdot 20)$, including five men with a negative FCV and FCS. Only one subject with RP had a false negative FSP(A). The duration of an attack of $R P$ was 1.5 minutes $(1->15)$ at FCV in 17 subjects. In seven men with RP totally four thumbs and four index fingers showed signs of RP at the hand cooling test, although these fingers had never been noticed as showing episodes of RP previously. Considering the finger used at pressure measurements (FSP-finger), ten men had a zero pressure and negative colour tests whereas none had a negative $\operatorname{FSP}(0)$ test and a positive FCV or FCS $(p<0.01)$. Six men had negative colour tests in the FSP finger and a positive FCV or FCS in one or more of the other four fingers, whereas none had a positive FCV or FCS in the FSP finger and negative colour tests in the other fingers $(p<0.05)$.

\section{Discussion}

In the present study the medical interview had a high five year reproducibility $(k=0.94)$. An attack of $R P$ was objectively detected as a zero pressure in the cooled finger or as finger colours of RP after hand cooling. FCV, FCS, and FSP(0) showed no significant differences in sensitivity or specificity with regard to detecting an episode of RP. This indicates that the colour tests are as valuable as FSP(0) for diagnostic purposes. The values of $74 \%$ and $57 \%$ in sensitivity of FSP(0) and FCV suggest that FSP(0) might be superior to FCV in a study with larger numbers than the present one. The design of the study, however, may disfavour the colour tests as the preceding finger cooling at pressure measurements might have weakened the cold response of this finger when recooled for the colour tests. ${ }^{8}$ Actually, the fingers examined with both cooling methods had a positive colour test less often than a zero pressure and they had fewer positive colour tests than other (less affected) fingers of the same hand. The diagnosis by FCV was confirmed by FCS, which had a kappa coefficient of 0.93 for repeated evaluations of the slides of the photographed hand. Non-affected fingers showed episodes of RP during the colour tests in some of the exposed men with and without RP. This indicates the existence of non-symptomatic RP in exposed men with and without RP, which is in agreement with other studies. ${ }^{616}$ All false positive $\operatorname{FSP}(0)$ were associated with a positive colour test or a history of previously active VWF. This indicates that all positive $\mathrm{FSP}(0)$ were true positive test results and that the diagnosis by interview is not a valid method for detecting subclinical cases of RP. The false negative test results of FSP $(0)$ represented subjects in stages 2 and 3 without significant difference in stage preference. The diagnostic value of $\operatorname{FSP}(0)$ was in accordance with those of our previous studies $(\mathrm{p}>0.20){ }^{813}$

The sensitivities of $\operatorname{FSP}(0)$ and $\operatorname{FSP}(A)$ in the present study seem to be higher than in others. ${ }^{5617}$ This may be due to the possible milder cases studied by others, ${ }^{5617}$ but may also be due to the omission of body cooling, the use of a higher room temperature, ${ }^{6}$ prewarming of the fingers at $42^{\circ} \mathrm{C},{ }^{6}$ or the use of $10^{\circ} \mathrm{C}$ as the lowest finger temperature. ${ }^{5617}$ Thus it has been shown that body cooling ${ }^{18}$ and a low room temperature $^{19}$ facilitate the provocation of RP. The specificity of FSP(A) in exposed workers was lower than those of most other studies. ${ }^{56}$ This may also be explained by differences in the subjects. It may additionally suggest that the use of body cooling, a low room temperature, or a low cooling temperature of the finger, or a combination of these, as used in the present study facilitate the detection of vibration induced abnormalities of the cold response in exposed subjects without RP. ${ }^{8}$ The sensitivity of the present colour tests were similar to those of other studies. ${ }^{162021}$

The hand cooling test used here had the following modifications: a body precooling of 30 minutes duration with the intention of increasing the activity of the central sympathetic nervous system, ${ }^{22}$ a hand cooling performed during five minute ischaemia to obtain a well defined temperature of the digital arteries, ${ }^{2}$ and a blind evaluation of the finger colours from slides of the photographed hand and colour plate with the intention of objectifying and "freezing" the pattern of finger colours, which may be of short duration as here.

Only one previous study has compared the hand cooling test with FSP(A) in the same population. ${ }^{6}$ An equal but low sensitivity of both tests $(25 \%, n=25)$ was found in workers with active VWF. Contrary to this result the present findings showed a much higher sensitivity of FSP(A) $(96 \%, n=23)$ when compared with that of FCS $(61 \%)$ and FCV (57\%). FSP(A), however, only detects if a cold response is abnormal or not. Thus FSP(A) does not measure an episode of RP with complete closure of the arteries despite its high "sensitivity." 7 Furthermore, an abnormal FSP(A) is not a diagnostic criterion for RP because of its relative low specificity $(64 \%)$ in the exposed workers of the present study.

FSP(0) has not previously been compared with other diagnostic tests in the same population. The results of the present study indicate equal diagnostic values of FCV, FCS, and FSP(0) in exposed workers. Thus a finger colour test is recommended for diagnostic purposes in workplaces and occupational health centres as this method is cheaper and easier to perform than a FSP(0) test. The pressure measurements may be of guidance in detecting non-symptomatic exaggerations of the vasoconstrictor response to cold ${ }^{8}$ in the control of vibration dampening measures,${ }^{23}$ and in the 
monitoring of the effect of medical treatments for VWF. $^{2425}$

The material of the study was partly procured in collaboration with Morten Vinter, MD, Occupational Health Centre of the City of Copenhagen. The investigation was supported by the Danish Working Environment Fund and the University of Copenhagen.

\section{References}

1 Pyykkö I. Clinical aspects of the hand-arm vibration syndrome. A review. Scand J Work Environ Health 1986;12:439-47.

2 Nielsen SL, Lassen NA. Measurement of digital blood pressure after local cooling. J Appl Physiol 1977;43:907-10.

3 Yodaiken RE, Jones E, Kunicki R. The Raynaud phenomenon of occupational origin. Advanced Microcirculation 1985;12:6-33.

4 Färkkilä M. Vibration induced injury. Br J Ind Med 1986;43: 361-2.

5 Ekenvall L, Lindblad LE. Vibration white finger and digital systolic pressure during cooling. Br J Ind Med 1986;43:280-3.

6 Pyykkö I, Färkkilä M, Korhonen O, Starck J, Jäntti V. Cold provocation tests in the evaluation of vibration-induced white finger. Scand J Work Environ Health 1986;12:254-8.

7 Lewis T. Experiments relating to the peripheral mechanism involved in spasmodic arrest of the circulation in the fingers, a variety of Raynaud's disease. Heart 1929;15:7-101.

8 Olsen N, Nielsen SL, Voss P. Cold response of digital arteries in chain saw operators. $\mathrm{Br} J$ Ind Med 1982;39:82-8.

9 Taylor W, Pelmear PL. Vibration white finger in industry. London: Academic Press, 1975:xvii-xxii.

10 Allen EV, Brown GE. Raynaud's disease: a critical review of minimal requisites for diagnosis. Am J Med Sci 1932;183:187200.

11 Pyykkö I, Sairanen E, Korhonen O, Färkkilä M, Hyvärinen J. A decrease in the prevalence and severity of vibration-induced white fingers among lumberjacks in Finland. Scand $J$ Work Environ Health 1978;4:246-54.

12 Hirai M, Nielsen SL, Lassen NA. Blood pressure measurements of all five fingers by strain gauge plethysmography. Scand J Clin Lab Invest 1976;36:627-32.

13 Olsen N, Nielsen SL. Diagnosis of Raynaud's phenomenon in quarrymen's traumatic vasospastic disease. Scand $J$ Work Environ Health 1979;5:249-56.

14 Hirai M. Arterial insufficiency of the hand evaluated by digital blood pressure and arteriographic findings. Circulation 1978; 58:902-8.

15 Koran LM. The reliability of clinical methods, data and judgments. N Engl J Med 1975;293:642-6.

16 Pyykkö I. The prevalence and symptoms of traumatic vasospastic disease among lumberjacks in Finland. A field study. Work Environ Health 1974;11:118-31.

17 Thulesius O, Brubakk A, Berlin E. Response of digital pressure to cold provocation in cases with Raynaud phenomena. Angiology 1981;32:113-8.

18 Nielsen SL. Raynaud phenomena and finger systolic pressure during cooling. Scand J Clin Lab Invest 1978;38:765-70.

19 Ekenvall L, Lindblad LE. Digital blood pressure after local cooling as a diagnostic tool in traumatic vasospastic disease. $\mathrm{Br}$ $J$ Ind Med 1982;39:388-91.

20 Agate JN. An outbreak of cases of Raynaud's phenomenon of occupational origin. Br J Ind Med 1949;6:144-63.

21 Kylin B, Gerhardsson G, Hansson J-E, et al. Hälso- och miljöundersökning bland skogarbetare. Stockholm: Arbetsmedicinska Institutet, 1968:44-52. (AI-rapport 5.)

22 Olsen N, Fjeldborg P, Brøchner-Mortensen J. Sympathetic and local vasoconstrictor response to cold in vibration induced white finger. Br J Ind Med 1985;42:272-5.

23 Olsen N, Nielsen SL. Vasoconstrictor response to cold in forestry workers: a prospective study. $\mathrm{Br} J$ Ind Med 1988;45:39-42.

24 Lagerkvist BE, Linderholm $\mathrm{H}$. Cold hands after exposure to arsenic or vibrating tools: effects of ketanserin on finger blood pressure and skin temperature. Acta Pharmacol Toxicol 1986; 58:327-32.

25 Larsen VH, Fabricius J, Nielsen G, Hansen KS. Ketanserin in the treatment of traumatic vasospastic disease. $\mathrm{Br}$ Med J 1986; 293:650-2. 